\title{
A CONSTRUÇÃO DO SER SINOPENSE POR MIGRANTES DA DÉCADA DE 80: MEMÓRIAS CULTIVADAS E ENRAIZADAS
}

\begin{abstract}
Ana Paula de Souza Pereira
Mestranda em Estudos Linguísticos pela Universidade do Estado de Mato Grosso

(UNEMAT)

anaunemat919@gmail.com

Cristinne Leus Tomé

Doutora em Educação pela Universidade Federal do Rio Grande do Sul (UFRGS) Professora da Universidade do Estado de Mato Grosso (UNEMAT)

cristinne.tome@unemat.br
\end{abstract}

\section{RESUMO}

Este artigo tem como objetivo apresentar a construção da identidade dos migrantes que vieram para Sinop Mato Grosso nos anos de 1980. Para tanto, foram realizadas entrevistas com quatro pessoas que residem na cidade. Como aporte teórico, respaldou-se nas reflexões de Stuart Hall, Tomás Tadeu da Silva, Edison Antonio de Souza, Luciana Texeira. Por meio das análises de dados, percebeu-se que, apesar de serem de outros estados brasileiros, os entrevistados afirmam que são filhos desta terra, reconhecendo-a como lugar de prosperidade econômica. Ademais, averiguou-se nos dizeres dos migrantes, que o desenvolvimento da cidade mescla-se com a construção da identidade dos entrevistados, ocasionando assim, outros sentidos ao ser sinopense.

Palavras-chave: migração, identidade, Sinop - Mato Grosso.

\section{ABSTRACT}

This article aims to present the identity construction of the migrants who came to Sinop - Mato Grosso in the 1980's and, for that, interviews were conducted with four people who live in the city. For the theoretical contribution, the work was based on the reflections of Stuart Hall, Tomás Tadeu da Silva, Edison Antonio de Souza, Luciana Texeira. Through the data analysis, it can be seen that, despite being from other states, people interviewed declare they are children of this land, by recognizing it as a place of economical prosperity. Furthermore, it was verified in the migrants' statements, that the city development combined with the interviewees' identity construction, causing this way, other meanings of being sinopense.

Keywords: migration, identity, Sinop Mato Grosso. 


\section{Considerações iniciais}

Sinop, cidade no estado de Mato Grosso, teve suas primeiras aberturas do traçado urbano logo após a derrubada da floresta em 1972. A partir desse momento, migrantes chegavam com frequência, permanecendo, em barracas, até o corte da madeira para as construções das casas, uma vez que, outro material de construção era inviável no momento. Em 14 de setembro de 1974, a cidade foi oficialmente fundada. Uma festa que teve desfile cívico na avenida principal, de chão batido, com a presença do ministro do interior, Rangel Reis, do senhor Ênio Pipino e João Pedro Moreira de Carvalho proprietários da empresa colonizadora Sociedade Imobiliária do Noroeste do Paraná (SINOP) e demais autoridades locais. Em 17 de dezembro de 1979, a cidade teve sua emancipação política desmembrando-se do município de Chapada dos Guimarães e formando o novo Município de Sinop (TOMÉ, 2009).

E assim sucedeu a migração com objetivo de colonizar Sinop. Vieram pessoas provenientes das regiões sul, sudeste e nordeste e, em menores proporções, de outras regiões, a fim de iniciarem novas atividades econômicas com base na propriedade da terra (OLIVEIRA, 1983). Durante a migração, as manifestações culturais individuais, familiares, locais e regionais vieram com os migrantes nessa expansão rumo ao centrooeste brasileiro, proporcionando um movimento identitário diversificado no contexto Amazônico. Nesse sentido, Hall (2003) ressalta que o papel das migrações foi além das econômicas, estreitando as fronteiras culturais, estabelecendo novas adaptações e maneiras de viver.

O presente estudo busca compreender o processo de construção da identidade sinopense em um recorte formado por migrantes da década de 1980. Posto isso, partimos 
do princípio de que a identidade é construída pelas significações que interpretamos ao longo da vida, em que o social e a diferença são bases para reconhecermos o que somos e o lugar ao qual pertencemos. Nesse contexto, nos embasamos teoricamente nos estudos culturais, já que concordamos com Silva (2010) ao refletirmos a cultura como um eixo na circulação de relações de poder. Nessa direção, o autor (2010, p. 15) apresenta que "os estudos culturais estão preocupados com questões que se situam na conexão entre cultura, significação, identidade e poder".

Desse modo, o artigo se estruturou da seguinte forma: no primeiro tópico trazemos um breve histórico da migração para Sinop. Por conseguinte, discorremos sobre as noções de identidade de acordo com os estudos culturais de Hall $(2006 ; 2014)$ e Silva (2014). E por fim, discorremos, no quarto tópico, a análise das entrevistas com os migrantes, e posteriormente as considerações finais da pesquisa.

\section{Em busca da terra prometida: breve histórico da migração para Sinop}

Em 1930, a política de Vargas abriu novos horizontes rumo à colonização matogrossense, tendo como meta o povoamento e desenvolvimento dessa área até então desprestigiada. Convém lembrar que a vinda para Mato Grosso adveio "[...] da necessidade de uma ocupação do território e fixação de fronteiras geográficas." (CASTRO et al., 1994, p. 60). Segundo os autores, essas ações eram denominadas como 'Marcha para o Oeste'. Nesse momento, iniciou-se de maneira institucionalizada e organizada o processo de migração para o estado de Mato Grosso, primeiramente por incentivo governamental e, posteriormente com o auxílio das colonizadoras privadas. Assim, segundo Castro et al. (1994, p. 62), "pretendia-se, por um lado, absorver excedentes 
populacionais de outras regiões brasileiras e, por outro, ocupar terras através da área privada". Nesse cenário, Cunha (2002, p. 91) aponta os objetivos e interesses pelas terras de Mato Grosso:

O avanço da colonização foi feito em ritmo diverso, conforme as áreas em que se implantavam projetos, se eram privados ou públicos, e os objetivos a alcançar. Havia numerosos empreendimentos empresariais que se preocupavam em fazer o desmatamento e semear gramíneas visando à pecuária de corte. Pode-se admitir, no processo de avanço da frente pioneira e da ampliação da fronteira agrícola, a sucessão de alguns interesses: a ação das madeireiras, a cultura da soja, o desenvolvimento de outras culturas (arroz, cana), o garimpo e, principalmente, a pecuária.

Muitas cidades foram fundadas com apoio das colonizadoras particulares, sendo a Sociedade Imobiliária do Noroeste do Paraná (SINOP) uma das mais influentes no norte do Estado em 1970. Teixeira (2009) frisa que o projeto de colonização da imobiliária SINOP S. A. era a implantação da Gleba Celeste, com aproximadamente $199.064,89$ mil hectares de extensão, área que mais tarde viria a ser as cidades de Vera, Cláudia, Santa Carmem e Sinop (em homenagem a Colonizadora). Inicialmente, o núcleo colonial da Gleba foi fixado na cidade de Vera, mas por falta de acesso rodoviário à BR 163, a empresa colonizadora preferiu mudar para a cidade de Sinop a fim de ter amplo acesso à rodovia, tendo em vista o translado de pessoas e a comercialização da produção, insumos e alimentos. Souza (2015, p. 123) expõe que,

no ano de 1972, iniciou-se a abertura da cidade de Sinop na altura do $\mathrm{Km} \mathrm{500,} \mathrm{no} \mathrm{senti-} \mathrm{do} \mathrm{Cuiabá-Santarém.} \mathrm{As} \mathrm{primeiras} \mathrm{casas} \mathrm{foram}$ construídas provisoriamente de lona e, mais tarde, de madeira. Foram iniciados também os serviços de desmatamento e terraplanagem, com abertura das primeiras ruas, avenidas e estradas vicinais. 
Os migrantes, que eram em sua maioria da região sul, almejavam uma terra livre das geadas que queimavam as plantações, além disso, queriam expandir o espaço de cultivo. De acordo com Cunha (2002), no início da colonização de Sinop, 69\% dos migrantes eram do Paraná; já em 1980, o percentual passou a ser de 50\%, dividindo espaço com migrantes paulistas, nordestinos e nortistas.

Por outro lado, mesmo com fluxo migratório intenso, era necessário atrair mais famílias. Para isso, a colonizadora investia nas propagandas que demonstravam o local como um espaço fértil e promissor, simplesmente um caminho ao El dourado. Essa expressão foi muito utilizada na época, assim como alguns slogans, a saber, "[...] 'Sinop em tempo de progresso', 'Sinop, a cidade que comanda o progresso da região', 'cidade de um povo ordeiro e trabalhador', 'Sinop: a marca do trabalho' e 'Sinop, cidade futuro'" (SOUZA, 2015, p. 125). Esses artifícios publicitários se proliferavam em outros estados, sendo muito relevante para a divulgação de Sinop como cidade potencial.

Porém, mesmo com tal marketing, muitos eram os desafios encontrados pelos migrantes, principalmente a falta de uma boa estrutura educacional ou acesso à saúde. Além disso, os lavradores enfrentaram dificuldades no cultivo. Texeira (2009, p. 125) enfatiza essa realidade ao explicar que

o método de cultivo utilizado pelos agricultores (o mesmo usado em seu estado de origem) não se adaptou às terras e ao clima da Amazônia mato-grossense e trouxe grandes prejuízos aos colonos. Dificuldades como a baixa produtividade agrícola, a crise do preço do café no comércio mundial, as doenças tropicais e a falta de estradas e infraestrutura, fizeram vários desses colonos abandonarem a região.

Dessa maneira, o agricultor, oriundo de um local frio, teve que se adaptar para cultivar e preparar a terra. Embora o ambiente fosse assustador, muitos permaneceram 
na localidade em virtude do desenvolvimento gradual da cidade e pela ambição de melhores condições de vida para os que eram economicamente desfavorecidos; e a ascensão financeira para as pessoas que já detinham um certo capital investido. Em suma, o cenário de Sinop, nos anos 70, foi de desbravar, adaptar e progredir.

Por conseguinte, Souza (2015) realça, na década de 1980, a ampliação da zona urbana e a melhoria nos serviços básicos que impulsionou o êxodo rural, ocasionando o aumento da densidade populacional urbana. Já na década de 1990, era visível o avanço dos latifundiários, bem como, o estabelecimento pecuário responsável pela a economia central da cidade e região. Cunha (2002) entende os anos 90 como um momento de investimento em tecnologias que fomentou a expansão agrícola, permitindo que Sinop, entre outras regiões mato-grossenses, se destacasse como seleiro do Brasil.

Neste século, Sinop se caracteriza como polo da região norte, sendo ponto de referência em muitos serviços. Além de ser uma cidade universitária, que conta com duas universidades públicas, duas privadas e dois institutos técnicos que garantem a formação dos profissionais. Essas instituições cravaram/cravam no município um importante papel, pois as implantações provocaram/provocam não só mais migrações de outros estados, mas a fixação das famílias que aqui criaram raízes.

Em síntese, a história de Sinop perpassou por diversas vértices, que vão desde o desbravamento da 'selva' ao urbanismo de 'excelência', sendo a cidade considerada como a Capital do Nortão. Essa situação de progresso está presente na memória dos migrantes, que ao irem para outra terra, vivenciaram uma outra possibilidade identitária, a de mato-grossense.

\section{Identidades: algumas conceituações}


Definir identidade para Hall (2006, p. 8) é algo “[...] complexo, muito pouco desenvolvido e muito pouco compreendido na ciência social." A partir dessa explanação, estabelecer um conceito cristalizado e fixo torna-se um desafio em meio a um mundo globalizado, pois para Hall (2003, p. 18), “[...] a identidade é irrevogavelmente uma questão histórica. Nossas sociedades são compostas não de um, mas de muitos povos. Suas origens não são únicas, mas diversas." Dizer então, qual é nossa origem, torna-se uma tarefa inconclusiva frente aos diversos fatores que caracterizam uma 'identidade' única, haja vista que assumimos posicionamentos e sofremos influências de culturas diversas.

Nesse intento, Hall (2003) ressalta que a globalização modificou não só as relações econômicas, como também, provocou um estreitamento de fronteiras impulsionando um aumento nas migrações. O autor (2014, p. 75) elucida que "precisamos vincular as discussões sobre identidade a todos aqueles processos e práticas que têm perturbado o caráter relativamente 'estabelecido' de muitas populações e culturas." Hall salienta a prática migratória como um dos fatores que influenciou o conceito de identidade, não mais restringindo a unificação, porém expandindo a conceituação no que se refere a construção em meio a diferença.

Silva (2014, p. 75) considera "[...] a diferença como um produto derivado da identidade. A identidade é a referência, é o ponto original relativamente ao qual se define a diferença." Logo, a identidade é constituída/construída através da relação com o social, o histórico, o cultural e o linguístico. Todavia, o sentimento de completude não se instaura tão facilmente, sempre estamos/estaremos ligados ao que já fomos, ao que 
vamos ser, numa busca constante de entendimento sobre o papel desempenhado na existência.

Ao pensarmos nessa conjuntura, visualizamos que as migrações e o acesso as informações abriram caminhos para identidades diversas. Hall (2006) chama atenção para o que ele denomina "crise da identidade" iniciada no final do Século XX. Esta foi ocasionada pela desestruturação de posições sólidas instauradas na sociedade. Possivelmente, essa virada foi impulsionada por discussões mais abertas sobre temáticas que envolviam sexualidade, religião, raça, entre outras elencadas pelo teórico.

Similarmente, "essas transformações estão mudando nossas identidades pessoais, abalando a ideia que temos de nós próprios como sujeitos centrados" (HALL, 2006, p. 1). Consequentemente, essa descentração do sujeito foi responsável pela fluidez de pensamentos, aumento de questionamentos e deslocamentos.

Segundo o autor, não há como estabilizar ou nomear os traços identitários que assumimos, uma vez que os sujeitos também mudaram a forma de ver o mundo, não tendo mais 'aquele apego' ao fixo. O que hoje se instaura é o sentimento de liberdade, uma 'eterna busca' por melhores condições de vida em outro lugar ou situação. Dessa forma, Hall (2006, p. 75) destaca que,

quanto mais a vida social se torna mediada pelo mercado global de estilos, lugares, pelas imagens... mais as identidades se tornam desvinculadas, desalojadas de tempos, lugares, histórias e tradições específicas e parecem flutuar. Somos confrontados por uma gama de diferentes identidades (cada qual nos fazendo apelos, ou melhor, fazendo apelos as diferentes parte de nós).

Silva (2014, p. 78) enfatiza que "afirmar a identidade significa demarcar fronteiras, significa fazer distinções entre o que fica dentro e o que fica fora." Nesse intermeio, 
almejamos analisar como foi constituída a identidade dos migrantes que chegaram em Sinop na década de 80 , verificando quais os desafios enfrentados na sua vinda e os motivos que fizeram essas pessoas a adotarem a cidade como terra, já que todos residem no local a mais de 20 anos.

\section{Percurso metodológico}

Nesta seção, apresentaremos os processos metodológicos responsáveis pela evolução da pesquisa. Cabe enfatizar que o estudo foi de natureza qualitativa, Ludke (1986, p. 11) descreve que "a pesquisa qualitativa tem o ambiente natural como sua fonte direta de dados e o pesquisador como seu principal instrumento." Destacando-se aqui que esta pesquisa promove a aproximação entre o pesquisador e o pesquisado no contexto científico.

Primeiramente, fizemos uma revisão bibliográfica a fim de compreendermos a colonização de Sinop e o conceito de identidade. O estudo bibliográfico, segundo Marconi e Lakatos (2003, p. 44), “[...] pode ser considerado também como o primeiro passo de toda pesquisa científica". É nessa etapa, que o pesquisador se reitera teoricamente para as reflexões frente às análises.

Posteriormente, foi realizada a pesquisa a campo com a realização de quatro entrevistas. Optamos pela entrevista por ser um instrumento básico e preciso na coleta de dados. "A grande vantagem da entrevista sobre outras técnicas é que ela permite a captação imediata e corrente da informação desejada, praticamente com qualquer tipo de informante e sobre os mais variados tópicos" (LUDKE, 1986, p. 34). 
A pesquisa contou com a participação de 4 entrevistados que chegaram em Sinop na década de 80 , sendo que três responderam oralmente e um por escrito. Para o desenvolvimento das análises e para manter a privacidade dos participantes não iremos revelar seus nomes. Assim, iremos identificá-los como: Migrante 1, Migrante 2, Migrante 3 e Migrante 4, conforme características abaixo:

- Migrante 1: É do sexo feminino, natural de Toledo-Paraná; possui graduação em Pedagogia e atualmente é escritora e poetisa; veio para Sinop em 1986.

- $\quad$ Migrante 2: É do sexo feminino, natural de Marechal Rondon-Paraná, tem Ensino Fundamental completo; trabalha como diarista e veio para Sinop em 1980.

- $\quad$ Migrante 3: É do sexo Masculino, Natural de Araruna-Paraná, possui Ensino Médio completo pela Escola Nilza de Oliveira Pipino e trabalha como vulcanizador de pneus agrícolas. Veio para Sinop em 1983.

- $\quad$ Migrante 4: É do sexo Masculino, natural de Novo Progresso-Pará, possui Ensino médio completo; trabalha atualmente de maneira autônoma no ramo de buffet e veio para Sinop em 1985.

\section{Análise de dados: memórias, raízes históricas e identitárias do ser sinopense}

Apesar de Sinop ser uma cidade relativamente nova, observamos que o crescente avanço econômico e social não é uma perspectiva somente atual. Desde a sua fundação, já era considerada como um lugar de prosperidade, o que atraiu inúmeros migrantes o com intuito de trabalharem na terra sinopense. 
Diante desses fatos, buscamos, aqui, compreender como os migrantes se estruturaram em Sinop. Nesse caso, perguntamos aos entrevistados, qual era a visão que eles tinham ou que visão as pessoas passavam a eles referente a cidade de Sinop?

Migrante 1: Sempre fui de 'mete' a cara. Um amigo da gente veio para cá e voltou para Paraná falando muito bem daqui. Eu estava desempregada por motivos políticos. Eu e meu marido não pensamos duas vezes, agilizamos tudo. Entre muitas lágrimas da parentada toda que não aceitava nossa decisão, em seguida, rumamos à terra prometida. Novo rumo / novas oportunidades / futuro.

Migrante 2: Na época, o pessoal falava muito bem de Sinop, que Sinop estava dando muito bem, estava abrindo fábrica de mandioca para fazer álcool de mandioca, uma proposta de muito trabalho. Eu vim com a minha família, minha mãe, meu irmão, minhas irmãs, eu cheguei com 20 anos de idade.

Migrante 3: Eles falavam que Sinop era o novo El Dorado da madeira, falavam que ganhava-se muito dinheiro, que era uma terra de progressão.Então eu vim para ganhar a vida com 14 anos. Lá no Paraná, minha mãe trabalhava de bóia-fria, eu vim para mudar de vida e estou até hoje.

Migrante 4: Minha mãe falava que o Mato Grosso era terra de fartura, porque lá no Pará não tinha nada. Ai eu fiquei com aquele pensamento, quando crescer vou para Mato Grosso.Ninguém falava nada de Sinop no Pará, nada mesmo.Ai eu vim para Cuiabá, Sorriso, Peixoto, mas não gostei das cidades, principalmente Peixoto por causa da violência. Eu decidi ir embora e quando parei em Sinop na rodoviária, eu vi um lugar de prosperidade, apesar de não ter nada, decidir ficar, e nessa estou até hoje.

As falas dos migrantes são carregadas de vocábulos fortes, que nos apresentam a busca por oportunidades. Em frases como: 'a terra prometida', 'proposta de muito trabalho', 'o novo El Dourado da madeira', 'eu vi um lugar de prosperidade'. Verificamos, 
a imagem que se tinha de Sinop como um lugar de ascensão econômica. Ressaltamos a produção de álcool através da mandioca e a atividade madeireira. Para Texeira (2009, p. 61), “o processo de desmatamento da área forneceu sustentáculo ao desenvolvimento das cidades, pois a coleta e a comercialização da madeira foram um dos principais atrativos.", logo, o Migrante 3 ao denominar a cidade como o El Dourado da madeira, nos mostra que grande parte da economia da cidade dos anos 80 era provinda dessa obraprima.

Visualizamos nas respostas, também, aspectos semelhantes e contrários quanto a identidade de migrante dos entrevistados. As mulheres, por exemplo, vieram acompanhadas dos maridos e da família. Por esse viés, Cunha (2002, p. 102) menciona que nos "[...] períodos de 70/80 e 81/91 a grande parte da imigração era do tipo 'casal com filhos'.". Notamos, que a presença da família era uma das razões para a fixação nos locais, onde o anseio era conseguir prosperar na terra de riquezas.

Por essa ótica, Hall (2006, p. 81) aponta inúmeros fatores que podem causar a migração. Segundo o autor, as pessoas "[...] se mudam para os locais, onde se vêm os bens e onde as chances de sobrevivência são maiores." Geralmente, fogem de conflitos políticos, como podemos ver na fala da migrante 1 ou simplesmente querem um local que 'tenha algo', como no caso do Migrante 4, que utiliza a palavra 'nada' para ilustrar a não condição de permanecer em seu estado de origem.

Nessa conjuntura, Souza (2015, p. 121) demonstra que "chegando a esses novos espaços, esses migrantes passaram a construir novas relações que vão dar novos sentidos e significados às suas vidas." E, possivelmente a construção de outras identidades. Nesse intento, perguntamos aos entrevistados: Quando você chegou aqui, você se sentiu deslocado(a)? 
Migrante 1: Adorei chegar aqui, era uma divina aventura. Com todos os inúmeros obstáculos que o lugar possuía mesmo assim eu me senti muito bem aqui. Em tudo eu me sentia acolhida, bem recebida. Só me apavorada um pouco quando lembrava dos quase dois mil quilômetros de distância de toda nossa família. Só... Sozinha... sem ninguém de parente por perto.

Migrante 2: É a gente se sentiu meio perdido, porque lá em Marechal Rondon já era uma cidade grande, então quando a gente chegou aqui, muito mato, tudo muito difícil, a gente veio de Cuiabá para Sinop, nossa! Uma calamidade. Não tinha asfalto. Não tinha nada. Foi muito difícil até chegar aqui.

Migrante 3: Aquela época só tinha madeireira em Sinop, não tinha urbanização, a moeda corrente da cidade era madeira. A cidade só tinha tora queimando na [Rua]Tarumãs e o resto era só barraco. Eu não me senti deslocado, mas pensa sair do Paraná, onde só tinha asfalto, e chegar aqui em uma cidade onde tinha dois momentos: poeira e lama foi difícil, a energia também era regrada, então foi difícil, mas é vida nova que seguiu.

Migrante 4: Me senti muito deslocado, não conhecia ninguém, ainda peguei uma malária, fiquei sozinho no hotel Star, doente por uns 15 dias.

Com base nos trechos, podemos averiguar o deslocamento que os migrantes sentiram ao chegarem em Sinop. A primeira impressão aparentou ser um choque, atrelado principalmente à paisagem da cidade, ainda primitiva em comparação aos lugares bem urbanizados. Apesar da 'calamidade' como se refere a Migrante 2, a concepção de progressão pesou mais para o estabelecimento na cidade.

De acordo como Souza (2015, p. 123), o cenário de Sinop era dividido em dois espaços: "[...] de um lado a natureza selvagem, e de outro, um mundo pequeno feito, 
pelo homem." Além dos fatores mencionados, a distância da família parece ser uma das fronteiras mais difíceis de serem superadas. Identificamos a palavra 'sozinha' na fala da Migrante 1, que diferente dos outros entrevistados não citou problemas referentes a estrutura do município, mas, sim, a saudade e o afeto como empecilhos para o estabelecimento no local.

Vale destacar o relato do Migrante 3, que novamente evidencia o poder exercido pelas madeireiras em Sinop, expondo o recurso natural como 'moeda corrente' da cidade. Percebemos que "[...] a atividade industrial (leia-se madeireiras) absorvia, em 1991, mais de $40 \%$ dos migrantes, situação que denota a força desse tipo de atividade na área" (CUNHA, 2002, p. 106). Na década de 80, a imagem de Sinop era o comércio da madeira, de certa forma uma marca identitária da cidade até os anos 2000.

Em virtude do deslocamento e dificuldades enfrentadas pelos entrevistados, questionamos a eles. Você teve/tem vontade de voltar para seu lugar de origem?

Migrante 1: Não! Cada dia menos, pois quando vou passear por lá tenho a real certeza de que quanto mais tempo fico longe, mas afasto de lá, mas é difícil.

Migrante 2: Não! Hoje eu não tenho mais vontade de voltar, agora a minha cidade é Sinop.

Migrante 3: Voltar para o Paraná nunca mais na vida.

Migrante 4: Eu não tenho vontade de voltar para o Pará, só vou para visitar a minha família. Eles ficam loucos para que eu volte para o estado, mas eu não quero. Já adotei os costumes, cultura, comida de Sinop, não me acostumo mais não [ao Pará]. Na época que eu vim, eu tinha certeza que aqui era meu lugar, estudei, trabalhei, coisa que era difícil na minha cidade. Hoje eu pertenço ao grupo de tradições gaúchas. 
Embasadas nesses depoimentos, podemos observar que os migrantes estabeleceram raízes profundas na cidade, como se o novo local fosse de fato o local de origem, o espaço onde os entrevistados fazem parte. Entretanto, por mais que a Migrante 1 reconheça essa terra, no desenrolar de sua fala sobressai uma incerteza. Notamos que a entrevistada utiliza vários marcadores afirmativos da não vontade de voltar ao seu lugar de origem, no entanto, ao final delimita 'mas é difícil'.

A conjunção adversativa (mas) na fala dessa migrante aparenta uma sensação de incompletude, assim como a frase: 'não! Cada dia menos', na qual visualizamos que, ao mesmo tempo que assinala uma vontade, explicita outra. Nessa perspectiva, Silva (2014, 102) explica que "a identidade está sempre escapando." Desse modo, estabelecer uma identidade única e imutável se torna impossível para os sujeitos dos processos globais.

Esta e a sensação familiar e profundamente moderna de Deslocamento, a qual - parece cada vez mais - não precisamos viajar muito longe para experimentar. Talvez todos nos sejamos, nos tempos modernos após a Queda, digamos o que o filosofo Heidegger chamou de unheimlicheit literalmente, "não estamos em casa" (HALL, 2003, p. 17).

Mediante ao exposto, Hall (2006, p. 18) dialoga com Silva (2014) ao argumentar que "as identidades são contraditórias. Elas se cruzam e se deslocam mutuamente; as contradições atuam tanto na sociedade, o exterior do indivíduo, quanto em seu interior, nos seus pensamentos". Tal constatação, reflete que a identidade não é dada no nascimento, não é completada com a interação; a identidade é construída e descontruída nas práticas humanas e sociais ao longo da vida. "Como vimos, dizer 'o que somos' significa também dizer o que não somos" (SILVA, 2014, p. 56). 
Convém ressaltar ainda, a resposta do Migrante 4, que compreende Sinop como seu lugar, considerando que se acostumou com as manifestações culturais, chegando citar até a comida e os costumes. Parafraseando Hall (2006, p. 97), essa ligação cultural é algo natural no processo migratório, sendo responsável pela criação de multiculturidades, além de estabelecer "[...] uma vertente de miscigenação, mistura e criação de novas significações que leva a um deslocamento".

Dessa maneira, analisamos que o Migrante 4, natural do estado do Pará, conviveu/convive com diversas culturas, fazendo parte até de um grupo de tradições gaúchas da cidade. Como já mencionado anteriormente por Cunha (2002), Sinop foi colonizada em maior número por paranaenses, porém o município também recebeu muitos pioneiros do Rio Grande do Sul. Por essa razão, há no cenário sinopense uma relevante influência sulista. Souza $(2015$, p. 127) reflete que,

a partir da diversidade cultural dessa cidade de fronteira, a aquisição de novos hábitos foram incorporados ao processo de construção sociocultural, fato que proporciona uma característica peculiar da realidade existente e vivida pelos habitantes nos seus espaços sociais e culturais, ou seja, a forma pela qual a população age e vive a sua cotidianidade. Esta é realçada pelo estilo da construção de suas casas, tradições, costumes, hábitos alimentares e de lazer (festas religiosas, práticas culturais etc.) que os migrantes trouxeram.

Os trechos expostos, acima, apresentam uma construção do passado de Sinop e de como os entrevistados sentem-se parte dessa terra. Entre histórias e relatos emergem nas palavras dos migrantes, traços de como a cidade significou na composição da vida pessoal de cada um; reflexos que nos fizeram questionar se eles consideravam sinopenses? 
Migrante 1: As razões que me fazem bater no peito e dizer: sou sinopense!, sim são bem lógicas. Se é aqui que eu encontro o meu espaço para viver com minha família, tenho mais é que erguer as mãos para o céu e agradecer a Deus com a certeza que ninguém é mais sinopense que eu. Sinto que Sinop gosta de mim. Sinop, esse é seu lugar. É um lugar que nunca parou de crescer. Que oferece um leque enorme de instituições de ensino superior e isso por si só, já galgaria razões suficientes para ser reconhecida como Sinop, esse é meu lugar.

Migrante 2: Eu me sinto. Porque todos esses anos a gente já trabalhou tanto aqui, a gente ajudou a construir praticamente Sinop, trabalhamos muito, tanto eu como a minha família. Então, assim, a gente tem uma história aqui. Me sinto mais do que no Paraná, porque aqui a gente já se firmou bem, aqui pra mim é tudo.

Migrante 3: Eu me considero sinopense porque eu vim para cá com 14 anos, nem sei o que [se] come no Paraná, eu conheço todas as crenças e festas do Mato Grosso, então eu me considero mato-grossense de coração, nem sei o que é ser paranaense. Para mim Sinop é tudo, aqui vivo bem, tenho minha família e vou morrer em Sinop. Eu sou sinopense de coração e alma.

Migrante 4: Eu falo para minha família, eu sou sinopense e que quando eu morrer quero ser enterrado aqui, eu não quero ser levado daqui não, eles querem me levar de volta, mas eu não quero. Eu tenho maior orgulho daqui, quando alguém me fala: Você é de onde? Eu falo: Sou de Sinop. Não falo que eu sou do Pará. Sou apaixonado, pertenço a essa terra.

Nesses dizeres, verificamos que os entrevistados sentem-se sinopenses. Em muitos momentos percebemos o orgulho em falar desse espaço, onde edificaram sonhos e trabalhos. A Migrante 1 fala assim: 'Sinop gosta de mim' e 'me fez crescer'. Tais frases nos fazem pensar sobre o pertencimento a esse local, pois a mesma chega a mencionar que ninguém é mais sinopense do que ela, fato que marca Sinop como ponto de sua origem, ou seja, uma autoafirmação que a diferencia dos outros. Silva (2014, p. 51) aponta que "[...] da mesma forma, as afirmações sobre a diferença só fazem sentido se 
compreendidas em sua relação com as afirmações sobre a identidade". Dizer que "ela é chinesa, significa dizer que 'ela não é argentina', 'ela não é japonesa', etc." Dessa maneira, ao proferir ser sinopense, a migrante se reconhece e delineia sua identidade, como se a declaração fosse um marcador de que não sou de outro lugar.

Os significados são basicamente instáveis, apesar de sempre procurar seu fechamento (a identidade) são permanentemente perturbados pela diferença, ou seja, pela oposição ao outros. Equivale a dizer que se mudarmos o significado de "dia", automaticamente também estaremos modificando o significado de "noite", afinal o significado de um dá-se somente em oposição ao outro (HALL, 2006, p. 41).

No bojo das reflexões desenvolvidas acima, a Migrante 2 expõe, igualmente, a honra de ter feito parte da construção da cidade, ao mesmo tempo observamos em sua fala que junto da estruturação de Sinop adquiriu uma nova identidade. Como se o trabalho de progressão do município fortalecesse o sentimento de pertencimento à cidade.

Outro fator que evidencia essa identificação da localidade como parte de si, é o momento em que a Migrante se expressa assim: 'Sinop é tudo para mim', nesse trecho, temos a ideia de que a entrevistada é de Sinop não pelo significado que temos sobre um adjetivo gentílico, mas pela história 'firmada' no município.

$\mathrm{Na}$ fala dos Migrantes 3 e 4, percebemos pontos importantes para entendermos como 'funciona' a identidade. Segundo os estudos de Hall e Silva (2014), a identidade é um processo em construção e de constante deslocamento. Nesse viés, o entrevistado 3 se manifesta dizendo: 'me considero sinopense e mato-grossense'; afirmando não saber o que é ser paranaense. Nessas marcas, compreendemos que, ora as identidades de pertencimento se encontram e ora se distanciam, pois ao determinar 'considero', o 
migrante assinala que não originou-se dessa terra, entretanto escolheu a cidade como seu lugar, numa forma de explicar sua origem. Entendemos que, "a identidade não é fixa, estável, coerente, unificada, permanente. A identidade tampouco é homogênea, definitiva, acabada, idêntica, transcendental. Por outro lado, podemos dizer que a identidade é uma construção, um efeito, um processo de produção" (SILVA, 2014, p. 66).

É importante observar que demarcar uma identidade é um trabalho constante, interpelados pelos aspectos sociais, culturais e linguísticos que nos circundam. Nesse intento, o Migrante 3 e 4 ao elencarem 'vou morrer aqui' e 'quero ser enterrado aqui', refletem o amor à Sinop numa tentativa de fixar-se a essa terra, mesmo que seja pela representação simbólica de ser enterrado em solo sinopense. Como se o fato de ser sepultado aqui significasse 'fazer parte' igualmente os que nasceram em solo sinopense.

Contudo, visualizamos que os entrevistados se reconhecem como sinopense, bem como atrelam o sucesso de desenvolvimento pessoal à cidade. E, embora sejam de outros estados, o sentimento de pertencimento ao município se funde com orgulho de terem sidos auxiliadores na edificação e história de Sinop. Em suas falas, sobressaem vocábulos de exaltação a cidade como lugar de prosperidade e sucesso.

Ademais, os sentidos que os identificam como frutos de Sinop são nítidos em suas falas, em que, o 'ser sinopense', representa uma das identidades dos migrantes na complexa teia dos traços identitários, que Hall (2006) e Silva (2014) explicam. Em suma, o ser/pertencer dos entrevistados se entrelaçam em memórias cultivadas e enraizadas na considerada Capital do Nortão.

No entanto, convém citar, ainda, a visão positiva dos entrevistados acerca do estabelecimento na cidade. Nesse sentido, ligamos esse olhar positivo ao sucesso que encontraram nessa terra, uma vez que todos residem em Sinop não tendo a vontade de 
retornar para o seu lugar de origem. Além disso, a migração, como citado anteriormente, é provocada pela falta de condições econômicas, fuga de conflitos, entre outras dificuldades. Sendo assim, entendemos que os migrantes não tiveram esses tipos de problemas na fixação em Sinop onde moram até hoje.

\section{Considerações finais}

Com base no levantamento teórico e analítico, averiguamos que a história de Sinop, apesar de recente, dilui-se com o percurso individual de cada entrevistado, se inscrevendo também em suas identidades e memórias. Compreendemos a partir dos dizeres, que o fator gentílico não se torna superior à construção de uma identidade pautada em anos de dedicação à cidade.

Diante do exposto, observamos que Sinop significa muito mais que um local de sobrevivência, é um pedaço da 'alma e do coração' dos migrantes. Tal expressão parece nos fazer alusão a versos poéticos de um poema ufanista, no entanto, são recortes das falas dos entrevistados que simbolizam a gratidão aos mais de trinta anos vividos em Sinop.

Esperamos, por meio desse estudo, instigar as pesquisas voltadas para Sinop, pois enfatizamos a importância de se falar do lugar ao qual pertencemos como forma de escrever a história da cidade, e assim 'delinear' suas identidades plurais.

Nesse sentido, ser sinopense é se deslumbrar com a mixagem de tradições de várias partes do Brasil. O município tem como particularidade a diversidade cultural possibilitada pelo grande fluxo de migrantes tanto do passado como do presente. Tal contexto oportuniza uma série de costumes. Podemos, aqui, citar, o próprio chimarrão 
dos sulistas em contraste com o famoso tereré do Mato Grosso do Sul ou, simplesmente, ressaltar a variedade de comidas interestaduais nas festas regionais, perpassando pelo tradicional churrasco, Maria Isabel (Prato típico do nordeste), açaí, entre outros alimentos incorporados ao cardápio de Sinop.

Em vista de todo esse processo, o cenário de Sinop nos anos $70^{i}$ foi de desbravar, adaptar e progredir. O cenário da década de 80 foi o de estabelecimento e melhoria dos serviços públicos a fim de promover a fixação e vinda de migrantes, pois esse momento era caracterizado pela falta de mão de obra e oportunidades de emprego. Já em 90 , a preocupação foi de expansão econômica, bem como a implementação de cursos superiores para incentivar a permanência dos filhos dos migrantes que aqui concluíram o Ensino Médio, assim como atrair estudantes de outras regiões numa perspectiva a longo prazo.

Em suma, muitos são os questionamentos sobre qual cultura, ou costume é próprio de Sinop. Supomos que a construção da identidade do município não seja pautada em uma ou duas características, mas, sim, em uma interconexão de diversos estados que junto do povo mato-grossense contribuíram para a formação da Capital do Nortão.

\section{Referências}

CASTRO, S. P. et al. A colonização oficial em Mato Grosso: a nata e a borra da sociedade. Cuiabá: EdUFMT, 1994.

CUNHA, José Marcos Pinto da. A migração no centro-oeste brasileiro no período 1970/96: o esgotamento de um processo de ocupação. Campinas, SP: Ed. da UNICAMP, 2002. 
HALL, Stuart. Identidade cultural na pós-modernidade. 21. ed. Rio de Janeiro: DP\&A Editora, 2006.

Quem precisa da identidade? In: et al. (orgs.). Identidade e diferença: a perspectiva dos estudos culturais. Petrópolis, RJ: Vozes, 2014. p. 72-92. Da diáspora: identidades e mediações culturais. Belo Horizonte: UFMG; Brasília: Unesco, 2003.

LAKATOS, Eva Maria; MARCONI, Marina Andrade. Metodologia científica. São Paulo: Atlas, 2003.

LUDKE, Menga. Pesquisa em educação: abordagens qualitativas. São Paulo: EPU, 1986.

MIGRANTE 1. Migrante 1: depoimento [Maio-2018]. Entrevistadora: Ana Paula de Souza Pereira. Sinop-MT, 2018. 3 f. Entrevista concedida para a pesquisa sobre a identidade sinopense.

MIGRANTE 2. Migrante 2: depoimento [Maio-2018]. Entrevistadora: Ana Paula de Souza Pereira. Sinop-MT, 2018. Gravação digital (12, 2 MB). Entrevista concedida para a pesquisa sobre a identidade sinopense.

MIGRANTE 3. Migrante 3: depoimento [Maio-2018]. Entrevistadora: Ana Paula de Souza Pereira. Sinop-MT, 2018. 1 Gravação digital (11,1 MB). Entrevista concedida para a pesquisa sobre a identidade sinopense.

MIGRANTE 4. Migrante 4: depoimento [Maio-2018]. Entrevistadora: Ana Paula de Souza Pereira. Sinop-MT, 2018. Gravação digital (9,2 MB). Entrevista concedida para a pesquisa sobre a identidade sinopense.

OLIVEIRA, João Mariano de. A esperança vem na frente: contribuição ao estudo da pequena produção em Mato Grosso, o caso de Sinop. 1983. 144 f. Dissertação (Mestrado em Geografia) - Departamento de Geografia da Faculdade de Filosofia, Letras e Ciências Humanas da Universidade de São Paulo. São Paulo, 1983.

SOUZA, Edison Antônio de. SINOP: espaço e memória. In: DIAS, Marieta. et al. (orgs.). Amazônia: visão caleidoscópica. Recife: Pipa Comunicação, 2015. p. 121-146.

SILVA, Tomás Tadeu da. A produção social da identidade e da diferença. In: HALL, Stuart et al (orgs.). Identidade e diferença: a perspectiva dos estudos culturais. Petrópolis, RJ: Vozes, 2014. p. 50-71.

Documentos de identidade: uma introdução às teorias de Currículo. 3. ed. Belo Horizonte: Autêntica. 2010. 
TEIXEIRA, Luciana. A colonização no norte de Mato Grosso: o exemplo da Gleba Celeste. 2006. 118 p. Dissertação (Mestrado em Geografia) - Universidade Estadual Paulista UNESP, Presidente Prudente, São Paulo, 2006.

TOMÉ, Cristinne Leus. "Eu não sou professor, não": a presença do professor na cidade de Cláudia entre 1978 e 1988. 2009. 318 f. Tese (Doutorado em Educação) - Programa de Pós-Graduação em Educação, Faculdade de Educação, Universidade Federal do Rio Grande do Sul, Porto Alegre, 2009.

Recebido em 14 de setembro de 2018.

Aceite em 9 de dezembro de 2018.

'Este trabalho é um recorte de um estudo sobre migração na cidade de Sinop, Mato Grosso. 